\title{
Pneumococcal meningitis in Cuban children and adolescents: A fifteen years follow up
}

\author{
Dickinson Meneses Felix ${ }^{1}$, Rodríguez Ortega Misladys ${ }^{2}$, Toraño Peraza Gilda ${ }^{3}$ \\ ${ }^{1}$ Department of Epidemiology, Institute Pedro Kourí. La Habana, Cuba \\ ${ }^{2}$ Department of Epidemiology, Institute Pedro Kourí. La Habana, Cuba \\ ${ }^{3}$ Department of Microbiology, Institute Pedro Kourí. La Habana, Cuba
}

Correspondence should be addressed to: Dickinson Meneses Felix; DICKINSON@IPK.SLD.CU

Received date: 23 December 2013; Accepted date: 3 March 2014; Published date: 4 June 2015

Academic Editor: IOLANDA JORDÁN

copyright @ 2015. Dickinson Meneses Felix, Rodríguez Ortega Misladys, Toraño Peraza Gilda. Distributed under Creative Commons CC-BY 4.0

\begin{abstract}
Pneumococcal meningitis still remains a serious global threat for children and adolescents. The aim of this study was to assess main epidemiological features of Pneumococcal meningitis, some risks for fatality and major pneumococcal serogroup/serotypes and their potential coverage by the available pneumococcal conjugate vaccines. An observational study of 569 confirmed cases (1998-2012) was completed based on surveillance system. Incidence, case-fatality rate and seasonality were estimated. Association of different variables related with dead was assessed by using Relative Risk and its $95 \%$ confidence interval with $\mathrm{p}<0.05$ considered as significant. A common protocol was used for the isolation and identification of Streptococcus pneumoniae. Overall incidence reached 1.3 per $10^{5}$ population, with annual variations. Infants showed the highest incidence $\left(10.7\right.$ per $/ 10^{5}$ population) especially at $4^{\text {th }}$, $2^{\text {nd }}$ and $6^{\text {th }}$ month of age. Seasonality was confirmed in January-March. Overall case-fatality rate reached $23.2 \%$ with highest figures in infants. Delayed hospitalization $(\geq 24$ hours) showed association ( $p>0.05$ ) in 6-11, 12-14 and 15-19 years old (Relative Risk=3.61, 3.00 and 3.16 respectively). Proportion of $S$. pneumoniae isolates covered by commercial pneumococcal conjugate vaccines ranked 53.0-71.4\%. Pneumococcal meningitis affects predominantly infants and is particularly lethal in Cuba. Seasonal increase occurs in winter. Hospitalization $\geq 24$ hours may contribute to increase fatality. Main S. pneumoniae serogroups/serotypes circulating among Cuban children and adolescents are included in commercial pneumococcal conjugated vaccines. We emphasize the importance of continuous nationwide surveillance to achieve more comprehensive insights into pneumococcal epidemiology as well as their contribution to the assessment of future immunization strategies.
\end{abstract}

Keywords: Pneumococcal meningitis, epidemiology, pneumococcal conjugated vaccines.

Cite this Article as: Dickinson Meneses Felix, Rodríguez Ortega Misladys, Toraño Peraza Gilda (2015), " Pneumococcal meningitis in Cuban children and adolescents: A fifteen years follow up", Pediatrics Research International Journal, Vol. 2015 (2015), Article ID 596251, DOI: 10.5171/2015. 596251 


\section{Introduction}

Pneumococcal infections remain a major cause of severe disease in childhood worldwide. The World Health Organization has reported (2007) that most frequent clinical presentations are acute otitis media, bacteraemia, pneumonia, and meningitis, affecting in particular the young children. Globally, Pneumococcal meningitis (Pnm) is the most severe cause of communityacquired bacterial meningitis (CABM) in children aged less than 5 years as declared by Parent et al., (2005). According to Ispahani et al., (2004), the survivors have the highest incidence of sequel among all meningitis. The rising incidence of decreased susceptibility to penicillin and third generation cephalosporins among pneumococci, is also a cause of concern as MacMaster et al., (2002) mentioned.

The advent of pneumococcal vaccines provided a potential way of preventing pneumococcal infections effectively. Available pneumococcal conjugate vaccines can induce protection in children aged 2 months and are well-tolerated, decreasing considerably the incidence after their introduction as showed different studies by Clarke (2006), Tsai et al., (2008) and Hsu et al., (2009).

Surveillance systems are an essential tool for Public Health. It allows identifying cases, observing trends, and monitoring geographical changes and circulating etiological agents. In Cuba, CABM surveillance has been carried out since 1961. Pérez et al., (2010) reported an improved surveillance system: the CABM Surveillance which was implemented in 1998 as a part of the National Program for Control and Prevention of the Neurological Infectious Syndrome (NPCPNIS). It allowed identifying Streptococcus pneumoniae as the main causative microorganism of CABM and the most lethal, after a significant decrease of meningitis attributable to Neisseria meningitidis serogroups $\mathrm{A}, \mathrm{B}$ and $\mathrm{C}$ and Haemophilus influenzae type $\mathrm{b}$ following massive and continuous vaccination through National Immunization Program as reported by Dickinson et al., (2001) and Pérez et al., (2010).

The purpose of this paper was to describe the main epidemiological features of Pnm in children and adolescents, to assess the association of timely hospitalization with mortality, as well as to determine major serogroups and serotypes of $S$. pneumoniae responsible for community-acquired meningitis and their potential coverage by the available pneumococcal conjugate vaccines.

\section{Methods}

This observational study was based on CABM surveillance data from January $1^{\text {st }}, 1998$ to December 31st, 2012 including 569 Pnm reported cases (compatible clinical picture and the identification of S. pneumoniae directly from cerebrospinal fluid or blood) in Cuban children and adolescents, considering the date of the symptoms onset.

The annual incidence was calculated as the number of cases per $/ 10^{5}$ population by using Cuba Census annual population estimates from the Office for National Statistics in Cuba adjusted for age. Case-fatality rate (CFR) was calculated as the fatalities per 100 cases.

Seasonal variations were estimated by using Holt-Winters multiplicative test, considering seasonality when observing an increase above the trend of the cases monthly average value.

For the purpose of this research it was defined the delayed hospitalization when "the time elapsed between the symptoms onset and the hospitalization was equal or greater than 24 hours", considering that Public Health System implemented in Cuba since 1959, is based on nationwide free and universal health service for every citizen, allowing a prompt hospitalization and high quality medical assistance (Perez et al., 1999). The association between delayed hospitalization and death was estimated through the Relative Risk (RR) and its 95\% confidence interval (95\% CI) with $\mathrm{p}<0.05$ considered as significant, using either a Chisquared Test or Fisher's Exact Test as appropriate. 
The National Reference Laboratory at Institute Pedro Kourí (NRL-IPK) was responsible for the confirmation of $S$. pneumoniae isolates submitted from the hospitals, following the standard procedure proposed by World Health Organization (2003). For capsular serotyping, it was applied the swelling capsule reaction (Quellung reaction) by using Pneumotest reactive (Staten Serum Institute, Denmark) as recommended by the Pan American Health Organization and the National Health Institute of Colombia (2004).

The present study was approved by the Scientific Board at the IPK, but did not require approval from an Ethics Committee because the Cuban Ministry of Public Health is the governmental organization responsible for the collection of infectious disease notifications, hospital discharge records and population or laboratory surveillance. The management of these data for public health purposes does not require a patient's informed consent nor does it require any authorization regarding privacy laws in Cuba. For database analysis we used Excel 2007, EpiInfo 3.4 and Epidat 3.1 software.

\section{Results}

Throughout the study it was reported 569 cases of Pnm, for an annual average of nearly 37 cases and a mean age of 3.4 years old (Data not shown). Overall incidence was 1.3 per $10^{5}$ population. Infants showed the highest incidence (10.7 per $/ 10^{5}$ population), followed by children 1-5 years old (2.2 per $/ 10^{5}$ population). The rates in older children and adolescents remained below 1.0, ranking 0.3-0.5 per $/ 10^{5}$ population (Table 1 ).

Table 1: Incidence of Pneumococcal Meningitis stratified according

to age group.Cuba, 1998-2012.

\begin{tabular}{|c|c|c|c|c|c|c|}
\hline \multirow{2}{*}{ Year } & \multicolumn{7}{|c|}{ Age-group } \\
\cline { 2 - 7 } & $<\mathbf{1}$ & $\mathbf{1 - 5}$ & $\mathbf{6 - 1 1}$ & $\mathbf{1 2 - 1 4}$ & $\mathbf{1 5 - 1 9}$ & All \\
\hline $\mathbf{1 9 9 8}$ & 12.0 & 1.6 & 0.3 & 0.4 & 1.1 & $\mathbf{1 . 4}$ \\
\hline $\mathbf{1 9 9 9}$ & 10.7 & 2.9 & 0.9 & 0.6 & 0.7 & $\mathbf{1 . 7}$ \\
\hline $\mathbf{2 0 0 0}$ & 23.8 & 3.0 & 0.9 & 1.2 & 0.6 & $\mathbf{2 . 4}$ \\
\hline $\mathbf{2 0 0 1}$ & 15.9 & 2.0 & 0.6 & 0.6 & 0.3 & $\mathbf{1 . 5}$ \\
\hline $\mathbf{2 0 0 2}$ & 11.6 & 1.9 & 0.2 & 0.4 & 0.4 & $\mathbf{1 . 2}$ \\
\hline $\mathbf{2 0 0 3}$ & 14.0 & 2.7 & 0.8 & 0.8 & 0.1 & $\mathbf{1 . 6}$ \\
\hline $\mathbf{2 0 0 4}$ & 9.5 & 3.3 & 0.5 & 0.4 & 0.1 & $\mathbf{1 . 4}$ \\
\hline $\mathbf{2 0 0 5}$ & 8.9 & 2.2 & 0.2 & 0.4 & 0.4 & $\mathbf{1 . 1}$ \\
\hline $\mathbf{2 0 0 6}$ & 7.3 & 1.1 & 0.7 & 0.4 & 0.1 & $\mathbf{0 . 8}$ \\
\hline $\mathbf{2 0 0 7}$ & 8.3 & 1.6 & 0.1 & 0.4 & 0.1 & $\mathbf{0 . 8}$ \\
\hline $\mathbf{2 0 0 8}$ & 7.3 & 2.0 & 0.5 & 0.7 & 0.2 & $\mathbf{1 . 0}$ \\
\hline $\mathbf{2 0 0 9}$ & 8.0 & 1.8 & 0.1 & 0.5 & 0.6 & $\mathbf{1 . 0}$ \\
\hline $\mathbf{2 0 1 0}$ & 7.7 & 1.5 & 0.7 & 0.0 & 0.1 & $\mathbf{0 . 9}$ \\
\hline $\mathbf{2 0 1 1}$ & 8.6 & 2.2 & 0.5 & 1.2 & 0.0 & $\mathbf{1 . 2}$ \\
\hline $\mathbf{2 0 1 2}$ & 3.1 & 2.5 & 0.2 & 0.0 & 0.1 & $\mathbf{0 . 8}$ \\
\hline $\mathbf{0 v e r a l l}$ & $\mathbf{1 0 . 7}$ & $\mathbf{2 . 2}$ & $\mathbf{0 . 5}$ & $\mathbf{0 . 5}$ & $\mathbf{0 . 3}$ & $\mathbf{1 . 3}$ \\
\hline
\end{tabular}


Annual incidence of all ages as one, showed a peak in 2000 (2.4 per $/ 10^{5}$ population), with smaller increases in 2003 and 2004 followed by a steady decline, nearly 1.0 per $/ 10^{5}$ population. Age-group analysis also showed the main increases from 1998 to 2000, especially in infants, but also in 2003-2004. According to gender, it was reported 359 cases among male $(63.1 \%)$ and 210 cases in female (36.9\%) (Data not shown).

The uppermost annual rates were observed in infants, with the highest figure during 2000 (23.8 per $/ 10^{5}$ population). After that, a slow decrease was experienced, reaching an incidence of 3.1 per $/ 10^{5}$ population in 2012 (Table 1).
Along the period it was reported 206 cases among infants. Of them, it was possible to obtain the information about the age in months (or days) in 202 (98.0\%). Main frequency of cases was observed at $4^{\text {th }}$ $(12.4 \%), 2^{\text {nd }}(11.9 \%)$ and $6^{\text {th }}(10.9 \%)$ months of age. Increased CFR was observed in the majority of age groups (Table 2). During neonatal period it was reported a total of 15 cases $(7.4 \%)$ : 4 (26.7\%) patients were newborn and 3 died (CFR 75.0\%); eleven patients were 7-27 days olds (73.3\%) and only one died (CFR 9.1\%) (Data not shown).

Table 2: Cases, percent, fatalities and case-fatality rate of pneumococcal meningitis in infants according to age in months. Cuba, 1998-2012.

\begin{tabular}{|c|c|c|c|c|}
\hline Age (months) & Cases & \% & Fatalities & CFR \\
\hline$<1$ & 15 & 7.4 & 4 & 26.7 \\
\hline 1 & 13 & 6.4 & 3 & 23.1 \\
\hline 2 & 24 & 11.9 & 7 & 29.2 \\
\hline 3 & 12 & 5.9 & 1 & 8.3 \\
\hline 4 & 25 & 12.4 & 4 & 16.0 \\
\hline 5 & 14 & 6.9 & 6 & 42.9 \\
\hline 6 & 22 & 10.9 & 3 & 13.6 \\
\hline 7 & 20 & 9.9 & 4 & 20.0 \\
\hline 8 & 19 & 9.4 & 6 & 31.6 \\
\hline 9 & 15 & 7.4 & 10 & 66.7 \\
\hline 10 & 9 & 4.5 & 3 & 33.3 \\
\hline 11 & 14 & 6.9 & 4 & 28.6 \\
\hline
\end{tabular}

Case-Fatality Rate: CFR.

Monthly distribution analysis evidenced the highest numbers of cases in January, February and March (Data not shown).

Holt-Winters multiplicative analysis demonstrated the higher increases above trend of monthly average value (Root Mean Squared Error $=3.63)$ in January $(1.33 \%)$, February $(1.30 \%)$ and March (1.35\%), confirming the seasonality of Pnm by the dry and cold season (Figure 1). 


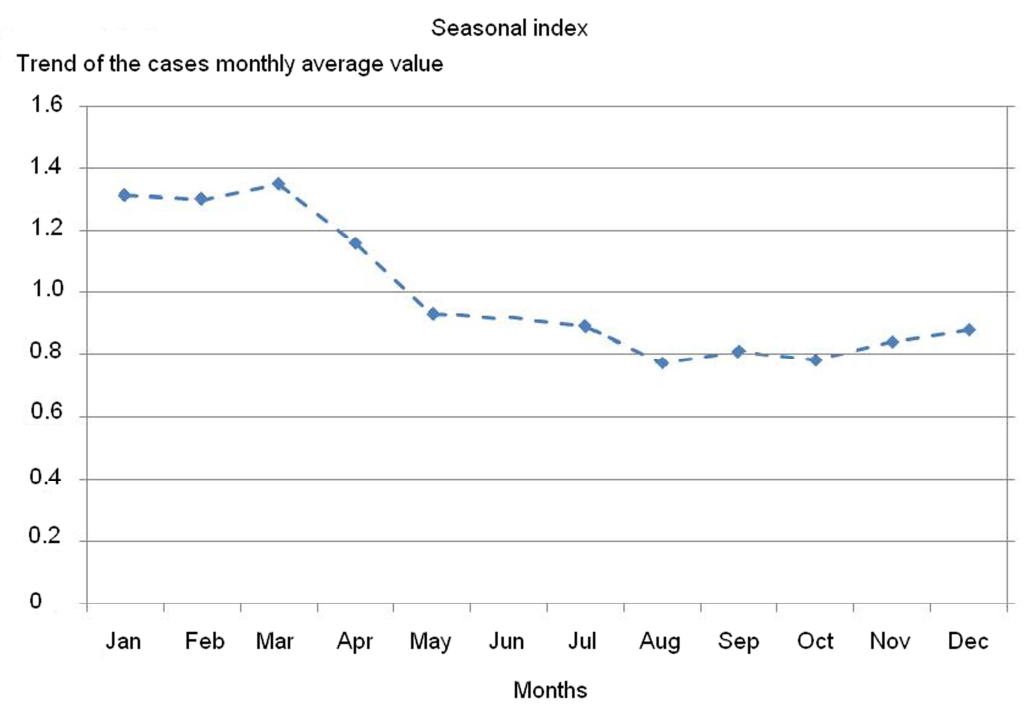

Figure 1: Seasonality of pneumococcal meningitis. Cuba, 1998-2012.

Table 3: Case-fatality rate of Pneumococcal Meningitis stratified according to age-group. Cuba, 1998-2012.

\begin{tabular}{|c|c|c|c|c|c|c|}
\hline \multirow{2}{*}{ Year } & \multicolumn{7}{|c|}{ Age-group } \\
\cline { 2 - 7 } & \multicolumn{1}{|c|}{} & $\mathbf{1 - 5}$ & $\mathbf{6 - 1 1}$ & $\mathbf{1 2 - 1 4}$ & $\mathbf{1 5 - 1 9}$ & All \\
\hline $\mathbf{1 9 9 8}$ & 27.8 & 33.3 & 0.0 & 50.0 & 0.0 & $\mathbf{2 3 . 3}$ \\
\hline $\mathbf{1 9 9 9}$ & 6.3 & 14.3 & 22.2 & 0.0 & 0.0 & $\mathbf{1 1 . 1}$ \\
\hline $\mathbf{2 0 0 0}$ & 23.5 & 40.9 & 11.1 & 33.3 & 0.0 & $\mathbf{2 6 . 3}$ \\
\hline $\mathbf{2 0 0 1}$ & 31.8 & 33.3 & 0.0 & 33.3 & 50.0 & $\mathbf{2 9 . 2}$ \\
\hline $\mathbf{2 0 0 2}$ & 31.3 & 21.4 & 0.0 & 0.0 & 0.0 & $\mathbf{2 1 . 6}$ \\
\hline $\mathbf{2 0 0 3}$ & 47.4 & 31.6 & 28.6 & 25.0 & 0.0 & $\mathbf{3 6 . 0}$ \\
\hline $\mathbf{2 0 0 4}$ & 25.0 & 17.4 & 25.0 & 0.0 & 0.0 & $\mathbf{1 9 . 0}$ \\
\hline $\mathbf{2 0 0 5}$ & 27.3 & 33.3 & 0.0 & 0.0 & 66.7 & $\mathbf{3 0 . 3}$ \\
\hline $\mathbf{2 0 0 6}$ & 25.0 & 28.6 & 16.7 & 0.0 & 0.0 & $\mathbf{2 0 . 8}$ \\
\hline $\mathbf{2 0 0 7}$ & 40.0 & 27.3 & 0.0 & 0.0 & 100.0 & $\mathbf{3 2 . 0}$ \\
\hline $\mathbf{2 0 0 8}$ & 0.0 & 30.8 & 25.0 & 33.3 & 0.0 & $\mathbf{2 0 . 0}$ \\
\hline $\mathbf{2 0 0 9}$ & 33.3 & 0.0 & 0.0 & 50.0 & 0.0 & $\mathbf{1 4 . 3}$ \\
\hline $\mathbf{2 0 1 0}$ & 11.1 & 0.0 & 0.0 & 0.0 & 100.0 & $\mathbf{8 . 0}$ \\
\hline $\mathbf{2 0 1 1}$ & 20.0 & 15.4 & 50.0 & 40.0 & 0.0 & $\mathbf{2 5 . 0}$ \\
\hline $\mathbf{2 0 1 2}$ & 50.0 & 20.0 & 0.0 & 0.0 & 0.0 & $\mathbf{2 2 . 7}$ \\
\hline Overall & $\mathbf{2 6 . 7}$ & $\mathbf{2 4 . 1}$ & $\mathbf{1 5 . 2}$ & $\mathbf{2 3 . 7}$ & $\mathbf{1 2 . 8}$ & $\mathbf{2 3 . 2}$ \\
\hline & & & & & & \\
\hline
\end{tabular}


A total of 132 fatal cases were reported during the study, for an average of 8.8 cases per year (Data not shown). Overall CFR reached $23.2 \%$ with highest figures in infants $(26.7 \%)$, children $1-5$ years old (24.1\%) and adolescents $12-14$ years old (23.7\%), while the lower CFR was observed in the adolescents 15-19 years olds (12.8\%). Annual CFR ranked between $36.0 \%$ (2003) and 8.0\% (2010), with annual variations (Table 3 ).

Fatalities were more frequent among male (90) than female (42), reaching CFR of
$25.1 \%$ and $20.0 \%$ respectively (Data not shown).

A total of 301 cases (52.9\%) were admitted timely to the hospital, 215 cases $(37.8 \%)$ were admitted with delay and in 53 cases $(9.3 \%)$ it was not possible to obtain the information about symptoms onset date. Univariate analysis evidenced association of delayed hospitalization with the fatal outcome in age-specific groups 6-11, 12-14 and 15-19 years old with RR of $3.61(95 \%$ CI 0.81-16.03 p>0.05), 3.00 (95\% CI 0.69$12.92 \mathrm{p}>0.05)$ and 3.16 (95\% CI 0-73-13.69 $\mathrm{p}>0.05$ ) respectively. When considering all age groups as one, association reach 1.63 (95\% CI 0.18-2.24 p>0.05) (Table 4).

Table 4: Association of delayed hospitalization to fatal outcome. Pneumococcal meningitis. Cuba, 1998-2012.

\begin{tabular}{|c|c|c|c|c|c|}
\hline \multirow{2}{*}{ Age group } & \multicolumn{2}{|c|}{ Delayed hospitalization } & \multirow{2}{*}{$\mathbf{R R}$} & \multirow[b]{2}{*}{$95 \% \mathrm{CI}$} & \multirow[b]{2}{*}{ p-value } \\
\hline & Yes & No & & & \\
\hline$<1$ & 71 & 113 & 1.66 & $1.01-2.70$ & 0.04 \\
\hline $1-5$ & 85 & 120 & 1.29 & $0.79-2.12$ & 0.29 \\
\hline $6-11$ & 30 & 31 & 3.61 & $0.81-16.03$ & 0.06 \\
\hline $12-14$ & 18 & 18 & 3.00 & $0.69-12.92$ & 0.10 \\
\hline $15-19$ & 11 & 19 & 3.16 & $0.73-13.69$ & 0.09 \\
\hline All & 215 & 301 & 1.63 & $1.18-2.24$ & 0.00 \\
\hline
\end{tabular}

The serogroups/serotypes of $S$. pneumoniae identified in children and adolescents with Pnm were 6A, 6B, 7F, 9N, 14, 15C, 18C, 19A, 19F and 23F. The most common were 6B (25.8\%), 6A (22.6\%), $19 \mathrm{~F}(12.6 \%)$ and 18C (9.7\%) Non-vaccine serogroups/serotypes isolated were $9 \mathrm{~N}$,
15C (Data not shown). The proportions of $S$. pneumoniae isolates that would be strictly covered by serotypes contained within the licensed 7 -valent, 10 -valent and 13-valent pneumococcal conjugate vaccines were $71.4,60.0$ and $53.8 \%$ respectively (Table 5).

Table 5: Distribution of Streptococcus pneumoniae serogroups/serotypes in infants with pneumococcal meningitis covered by the pneumococcal conjugate vaccines Cuba, 20002012

\begin{tabular}{|c|c|}
\hline \multicolumn{2}{|c|}{ Serogroup/serotype } \\
\hline Pneumococcal conjugate vaccines & $\begin{array}{c}\text { Isolates in Cuban infants included in } \\
\text { pneumococcal conjugate vaccines }\end{array}$ \\
\hline 7 -valent $(4,6 \mathrm{~B}, 9 \mathrm{~V}, 14,18 \mathrm{C}, 19 \mathrm{~F}, 23 \mathrm{~F})$ & $6 \mathrm{~B}, 14,18 \mathrm{C}, 19 \mathrm{~F}$ and $23 \mathrm{~F}(71.4 \%)$ \\
\hline 10 -valent $(\mathrm{PCV} 7+1,5,7 \mathrm{~F})$ & Previous $+7 \mathrm{~F}(60.0 \%)$ \\
\hline 13 -valent (PCV10 $+3,6 \mathrm{~A}, 19 \mathrm{~A})$ & Previous $+6 \mathrm{~A}(53.8 \%)$ \\
\hline
\end{tabular}




\section{Discussion}

Results from this study need to be interpreted considering some potential limitations. As occurs in many developing and transitional countries, microbiological identification of the causative microorganism in hospitals was not always possible to achieve, owing to laboratory practices, lack of supplies and/or diagnostic methods, as well as to previous antibiotic therapy. For this reason, the true number of Pnm cases might be slightly higher than reported by surveillance.

However, our study has several important strengths. First, this report represents one of the largest, longest and deepest epidemiological studies of Pnm in children and adolescents registered in Cuba so far. Second, it was based on a nationwide surveillance which was "useful and proficient providing and synthesizing critical and multidisciplinary information, fulfilling all suitable surveillance system attributes" (Perez et al, 2010, p.4), guaranteeing reliability of data. Finally, our research was performed in a geographically well-defined population where medical care for every citizen is nationwide, with total and free access to medical assistance, vaccination, and other health requirements.

S. pneumoniae have been identified as the major and most lethal agent causing bacterial meningitis in many region of the world, mainly in infants, as reported by the World Health Organization (2003), Jeena (2006) and Zaidi et al (2009). The extensive 15-year surveillance in Cuba identified incidence rates similar to those reported in high income countries by Jeena (2006), Vergison et al (2006), Theodoridou et al (2007) and Tsai et al (2008), but lower than those declared by Mwangi et al (2002) and Zaidi et al (2009) in less-developed and transitional countries. Cases in infants during neonatal period were only a few. Beyond this period, the age distribution was analogous to those reported by Ispahani et al (2004).

However, the decrease of incidence observed in Cuba, where pneumococcal vaccination has not been implemented to date, is complex to be elucidated only by means of the available surveillance data. Similarly, Pérez et al (2010) has reported an overall decrease of CABM in Cuba, probably as a result of prior nationwide massive and high coverage vaccinations, improvements in prevention and control of this group of diseases after the implementation of the National Prevention and Control Program for Neurological Infectious Syndrome, as well as the continuous development of public health and other social benefits accessible to the population. On the other hand, it could not be totally discarded the coincidence during the analyzed period of a low incidence phase as a part of a larger cyclic variation of disease (periodical long-lasting oscillations), but the available data do not allow to fully confirm this assumption.

After the use of $H$. influenzae type b conjugate vaccine targeted to children under 2 years old, Dickinson et al (2001) reported a sharp decline of meningitis caused by this pathogen during 1999. Simultaneously, Pnm increased appreciably from 1999 to 2000 (much more evident in infants), with a slow decrease onward. Explanation of this spiky increase may be multifarious. Most likely, the significant reduction of $\mathrm{Hib}$ after conjugate vaccination may have opened a niche for pneumococci, increasing their carriage in population, and therefore the exposure and likelihood to infection and disease as Auranen et al (2010) mentioned. Unfortunately, the existing data from surveillance are insufficient to fully corroborate this hypothesis. Replacement of bacteria and serotypes after conjugate vaccination has been previously suggested and documented in other countries by Simoes et al (2004), Von Gottberg et al (2007) and Sow et al (2009).

Differences in male/female specific incidence are coincident with those reported in other studies by Theodoridouet al (2007), Rossi et al (2009) and Mosavi-Jarrahi et al (2009), and are most likely related with some sex-specific differences in physical interaction and risk behavior previously mentioned by Hussein and Shafran (2000) and Rossi et al (2009).

Ortiz et al (2006), (2008) have described that climate in Cuba is tropical and seasonally wet. The months from May to October are generally hot and rainy, and those from November to 
April (winter, dry season) are characterized by lower ambient temperatures and precipitation. In our study, seasonality of Pmn was identified during dry and cold period (January-March), coincidently with Sow et al (2009). Dowell et al (2003) indicated that this pattern may be associated with gathering of families due to low temperatures. On the other hand, Greenwood (2006) observed that environmental factors during dry and cold season might be more advantageous to pneumococci as a consequence of damage to the mucosal defenses increasing the ratio of infections in case patients to carriers.

Case-fatality rate observed was upper than those reported by Haddy et al (2005) and Theodoridou et al (2007) in high income countries, despite the countrywide and full access public health system existing in Cuba.

Perez et al (2010) previously mentioned that mortality may depend on some factors: careseeking behaviour in the population, referral practices to hospitals, opportune diagnose, timely and quality of care, underlying conditions on the host and the virulence of the strains. Adequate management of Pnm certainly requires timely hospitalization and treatment. Delay in treatment may increase the risk of an unfavorable outcome as declared by Radetsky (1992). With the criteria accepted for this study, association of delayed hospitalization with fatal outcome was more evident in older children and adolescents, although no statistical significance was found, perhaps because the small number of cases in these groups. Influence of underlying conditions, as reported by Bingen et al (2008), poor and untimely recognition of symptoms (by patients or relatives), extremely virulent strains and other factors might explain these results but will require additional studies to better define.

S. pneumoniae serotype distribution may vary according to geographic region in accordance with previous results of Hausdorf, Siber and Paradiso (2001). In a research study by Gabastou et al (2008), serotypes 14,6B, 1, 5, $19 \mathrm{~F}$ and $18 \mathrm{C}$ are the most frequent reported in Latin America and the Caribbean region; all are included in 7-valent, 10-valent and 13-valent pneumococcal conjugated vaccines. Lagos et al (2008) in Chile identified serotypes 1 and 5 as the common cause of meningitis. Results in the present study reveal that serogroups/serotypes are coincident with some circulating in the region. Therefore, the use of available pneumococcal conjugated vaccines may induce a decrease of Pnm (and other clinical presentations of pneumococcal disease), preventing fatality, disability and neurological sequel particularly among children and adolescents.

In Cuba it has not been implemented vaccination against $S$. pneumoniae on a national scale until now, because of economical reasons. Introduction of a suitable pneumococcal conjugate vaccine in the future will reduce significantly the incidence of pneumococcal infections. At that time, the existing epidemiological and microbiological data will be essential as a baseline to compare further changes in behavior of the disease, the circulating serogroups/serotypes, as well as the impact of vaccination.

\section{Conclusion}

Meningitis caused by $S$. pneumoniae affects mostly the infants and is particularly lethal in Cuba. Seasonal increase occurs in dry and cold months. Delayed hospitalization contributes to increase fatality. Main $S$. pneumoniae serogroups/serotypes circulating in Cuban children and adolescents are included in commercial pneumococcal conjugated vaccines. We emphasize the importance of continuous nationwide surveillance to achieve more comprehensive insights into pneumococcal epidemiology as well as their contribution to the assessment of future immunization strategies.

\section{Acknowledgments}

We thank epidemiologists who were involved in the data collection and also to all our colleagues Heads of Provincial Programs for Prevention and Control of Infectious Neurological Syndrome, as well as other staff of the Infectious Neurological Syndrome 
Provincial Commissions for their cooperation.

\section{References}

1. Auranen, K., Mehtala, J., Tanskanen, A. and Kaltoft, M.S. (2010) "Between-strain competition in acquisition and clearance of pneumococcal carriage-epidemiologic evidence from a longitudinal study of day-care children,"American Journal of Epidemiology, 171 169-176.

2. Bingen, E., Levy, C., Varon, E., de La Rocque, F., Boucherat, M., d'Athis, P. et al. (2008) "Pneumococcal meningitis in the era of pneumococcal conjugate vaccine implementation," European Journal of Clinical Microbiology Infectious Diseases, 27 191-199.

3. Castañeda, E., Agudelo, C.I., Regueira, M., Corso, A., Brandileone, M.C., Brandão, A.P., maldonado, a. et al. (2009) "Laboratory-based surveillance of Streptococcus pneumoniae invasive disease in children in 10 Latin American countries: SIREVA II Project Group, 2000-2005," Pediatric Infectious Disease Journal, 28 265-270.

4. Clarke, S.C. (2006) "Control of pneumococcal disease in the United Kingdomthe start of a new era," Journal of Medical Microbiology, 55 975-980.

5. Dickinson F, Pérez A, Galindo $M$, and Quintana I. (2001) "Impact of vaccination against Haemophilus influenzae type $b$ in Cuba", Pan American Journal of Public Health, 10 (3) 169-173.

6. Dowell, S.F., Whitney, C.G., Wright, C., Rose, C.E. and Schuchat, A. (2003) "Seasonal Patterns of Invasive Pneumococcal Disease", Emerging Infectious Diseases, 9 (5) 73-79.

7. Gabastou J.M., Agudelo C.I., de Cunto M.C., Castañeda E., Silva A.P. and Di Fabio J.L. (2008) "Characterization of invasive isolates of $\mathrm{S}$. pneumoniae, H. influenzae, and N. meningitidis in Latin America and the Caribbean: SIREVA II, 2000-2005," Pan Am J Public Health, 24(1) 115.
8. Gessler, P. (2010) "Invasive pneumococcal disease in children prior to implementation of the conjugate vaccine in the Zurich region, Switzerland," Acta Pædiatrica, 99 1005-1010.

9. Greenwood, B. (2006) "Pneumococcal Meningitis Epidemics in Africa," Clinical Infectious Diseases, 43 701-703.

10. Haddy, R.I., Perry, K., Chacko, C.E., Helton, W.B., Bowling, M.G., Looney, S.W. et al. (2005) "Comparison of incidence of invasive Streptococcus pneumoniae disease among children before and after introduction of conjugated pneumococcal vaccine," Pediatric Infectious Disease Journal, 24 320-323.

11. Hausdorf, W.P., Siber, G. and Paradiso, P.R. (2001) "Geographical differences in invasive pneumococcal disease rates and serotypes frequency in young children," Lancet, 357 950952.

12. Hsu, H.E., Shutt, K.A., Moore, M.R., Beall, B.W., Bennett, N.M. and Craig, A.S. (2009) "Effect of Pneumococcal Conjugate Vaccine on Pneumococcal Meningitis," New England Journal of Medicine, 360 244-256.

13. Hussein, A.S. and Shafran, S.D. (2000) "Acute bacterial meningitis: a 12 year review," Medicine, 79 360-368.

14. Ispahani, P., Slack, R.C.B., Donald, F.E., Weston, V.C. and Rutter, N. (2004) "Twenty year surveillance of invasive pneumococcal disease in Nottingham: serogroups responsible and implications for immunization," Archives of Disease in Childhood, 89 757-762.

15. Jeena, P.M. (2006) "The burden of pneumococcal disease in children. Advances in the fight of this epidemic," Professional Nursing Today, 10(2) 16-22.

16. Lagos, R., Muñoz, A., San Martin, O., Maldonado, A., Hormazabal, J.C., Blackwelder, W.C. et al. (2008) "Age - and Serotype - Specific Pediatric Invasive Pneumococcal Disease: Insights from Systematic Surveillance in Santiago, Chile, 1994-2007," Journal of Infectious Diseases, 198 1809-1817. 
17. McMaster, P., McIntyre, P., Gilmour, R., Gilbert, L., Kakakios, A., Mellis, C. (2002) "The emergence of resistant pneumococcal meningitis-implications for empiric therapy," Archive of Disease in Childhood, 87 207-211.

18. Mosavi-Jarrahi, A., Esteghamati, A., Asgari, F., Heidarnia, M., Mousavi-Jarrahi, Y. and Goya, M. (2009) "Temporal analysis of the incidence of meningitis in the Tehran metropolitan area, 1999-2005", Population Health Metrics. [Online], [Retrieved May 13, 2010], http://www.pophealthmetrics.com/content/7 /1/19/

19. Mwangi, I., Berkley, J., Lowe, B., Peshu, N., Marsh, K., and Newton, C.R. (2002) "Acute bacterial meningitis in children admitted to a rural Kenyan hospital: increasing antibiotic resistance and outcome," Pediatric Infectious Diseases Journal, 21 1042-1048.

20. Ortiz, P.L., Pérez, A.E., Rivero, A., León, N., Díaz, M., and Pérez, A. (2006) "Assessment of human health vulnerability to climate variability and change in Cuba," Environmental Health Perspective, 114 (12) 1942-1949.

21. Organización Panamericana de la Salud e Instituto Nacional de Salud Colombia. 2004. "Programa de vigilancia de los serotipos y resistencia antimicrobiana de Streptococcus pneumoniae y Haemophilus influenzae. Manual de procedimientos del proyecto SIREVA II". [Online] 33 - 99, [Retrieved November 30, 2005],

http://www.paho.org/Spanish/AD/THS/EV/L ABS-manual-vigilancia-serotipos.pdf/

22. Ortíz, P.L., Pérez, A.E., Rivero, A., Pérez, A., Cangas, J.R. and Lecha, L.B. (2008) "Variability and climate change in Cuba: potential impact on the human health". Revista Cubana de Salud Pública. [Online] 34 (1). p. 0-0, [Retrieved June 9 , 2009], http://scielo.sld.cu/scielo.php?script=sci_artte xt\&pid=S0864-34662008000100008\&lng=es

23. Pérez, A., Dickinson, F., and LLANES, R. (2010) "Invasive meningococcal disease. Cuba 1983-2006," VacciMonitor, 19 (3) 8-12.
24. Pérez, A.E., Dickinson, F.O., and Rodriguez, M. (2010) "Community acquired bacterial meningitis in Cuba: a follow up of a decade", BMC Infectious Diseases. [Online] 10: 130. 1-9, [Retrieved December 10, 2010], http://www.biomedcentral.com/14712334/10/130/

25. Pérez A., Dickinson f., Baly A. and Martinez R. (1999). "The Epidemiological Impact of Antimeningococcal B Vaccination in Cuba," Mem Inst Oswaldo Cruz, 94 433-440.

26. Radetsky, M. (1992) "Duration of symptoms and outcome in bacterial meningitis: an analysis of causation and the implications of a delay in diagnosis," Pediatric Infectious Disease Journal, 11(9) 694-97.

27. Rossi, P.G., Mantovani, J., Ferroni, E., Forcina, A., Stanghellini, E., Curtale, F., et al. (2009) "Incidence of bacterial meningitis (2001-2005) in Lazio, Italy: the results of an integrated surveillance system". BMC Infectious Diseases. [Online]. 9: 13. 1-32, [Retrieved May 14 , 2010],

http://www.biomedcentral.com/14712334/10/130/

28. Simões L.L.P., Andrade A.L.S.S, Laval C.A, Oliveira R.M, Silva S.A, Martelli C.M.T. et al (2004) "Impact of Haemophilus influenzae b (Hib) vaccination on meningitis in Central Brazil," Revista de Saude Pública, 38(5) 664670.

29. Sorensen, U.B. (1993) "Typing of pneumococci by using 12 pooled antisera," Journal of Clinical Microbiology 31 2097-2100.

30. Sow, S.O., Tapia, M.D., Diallo, S., Keita, M.M., Sylla, M., Onwuchekwa, U., et al. (2009) "Haemophilus influenza type b conjugate vaccine introduction in Mali: impact on disease burden and serologic correlate of protection," American Journal of Tropical Medicine and Hygiene, 80. 1033-1038.

31. Theodoridou, M.N., Vasilopoulou, V.A., Atsali, E.E., Pangalis, A.M., Mostrou, G.J., Syriopoulou, V.P. et al. (2007) "Meningitis registry of hospitalized cases in children: epidemiological patterns of acute bacterial meningitis throughout a 32-year period", BMC 
Infectious Diseases. [Online]. p. 1-30. 7 (101), [Retrieved August 18, 2010], http://www.biomedcentral.com/14712334/7/101/

32. Tsai, C.J., Griffin, M.R., Nuorti, P. and Grijalva, C.G. (2008) "Changing epidemiology of pneumococcal meningitis after the introduction of pneumococcal conjugate vaccine in the United States," Clinical Infectious Diseases, 46 1664-1672.

33. Vergison, A., Tuerlinckx, D., Verhaegen, J. and Malfroot, A. (2006) "Epidemiologic Features of Invasive Pneumococcal Disease in Belgian Children: Passive Surveillance Is Not Enough," Pediatrics, 118(3) 801-809.

34. Von Gottberg, A., de Gouveia, L., Madhi, S.A., du Plessis, M., Quan, V., Soma, K., et al. (2006) "Impact of conjugate Haemophilus influenzae type $b$ (Hib) vaccine introduction in South Africa," Bulletin of World Health Organization, 84 811-818.

35. Winther, T.N., Kristensen, T.D., Kaltoft, M.S., Konradsen, H.B., Knudsen, J.D. and Birthe, H. (2008) "Invasive pneumococcal disease in Danish children, 1996-2007, prior to the introduction of heptavalent pneumococcal conjugate vaccine," Acta Paediatrica, 98(2) 328-331.
36. World Health Organization. (2003). "Manual for the laboratory identification and antimicrobial susceptibility testing of bacterial pathogens of public health importance in the developing world: Haemophilus influenzae, Neisseria meningitidis, Streptococcus pneumoniae, Neisseria gonorrhoeae, Salmonella serotype Typhi, Shigella, and Vibrio cholerae," [Online], World Health Organization [Retrieved January 22, 2004], http://www.who.int/entity/csr/resources/pub lications/drugresist/en/IAMRmanual.pdf?ua=1

37. Vaccine Assessment and Monitoring team of the Department of Vaccines and Biologicals. (2003). "WHO-recommended surveillance standards for surveillance of selected vaccinepreventable diseases," [Online] World Health Organization [Retrieved January 13, 2009], http://www.who.int/vaccines-documents/

38. World Health Organization. (2007) "Pneumococcal conjugate vaccine for childhood immunization-WHO position paper," Weekly Epidemiological Records, 82 93-104.

39. Zaidi, A.K.M., Khan, H., Lasi, R., Mahesar, W. and the Sindh meningitis Group. (2009) "Surveillance of Pneumococcal Meningitis among Children in Sindh, Southern Pakistan," Clinical Infectious Diseases 48 S129-135. 